\title{
FISH-CS - a rapid method for counting and sorting species of marine zooplankton
}

\author{
Christine M. Henzler ${ }^{1,2, *}$, Elizabeth A. Hoaglund ${ }^{1,2}$, Steven D. Gaines $^{1,2,3}$ \\ ${ }^{1}$ Marine Science Institute, and ${ }^{2}$ Department of Ecology, Evolution and Marine Biology, University of California Santa Barbara, \\ Santa Barbara, California 93106, USA \\ ${ }^{3}$ Present address: Bren School of Environmental Resource Management, University of California Santa Barbara, \\ Santa Barbara, California 93106, USA
}

\begin{abstract}
Understanding population dynamics in marine species has long been hindered by the inherent difficulties of studying species in which all or part of the life cycle is planktonic. Plankton sample processing is laborious and, due to morphological similarity between disparate taxa, often identifies zooplankton only to higher taxonomic levels. As a consequence, many scientific issues that require identification to species level are impossible to explore adequately. Several in situ hybridization protocols show promise for identifying marine larvae by color-coding them with taxon-specific, dye-labeled DNA probes. We adapted these protocols and coupled them with recent cell sorting technology to rapidly and accurately identify bivalve larvae from diverse plankton samples. We developed probes for 2 bivalve taxa: Musculista senhousia and the species complex Mytilus edulis/galloprovincialis/trossulus. Coupled fluorescence in situ hybridization and cell sorting (FISHCS) separated M. galloprovincialis larvae from both oyster Crassostrea gigas larvae and from a mixed plankton/M. galloprovincialis sample. The number of false positives and false negatives was assessed by a PCR assay. Our FISH-CS method is robust to plankton autofluorescence and can be easily adapted to work with nearly any planktonic species or life stage of appropriate size.
\end{abstract}

KEY WORDS: Fluorescence in situ hybridization . Oligonucleotide probe $\cdot 18 \mathrm{~S}$ rRNA · Marine larvae . Species identification

\section{Resale or republication not permitted without} written consent of the publisher

\section{INTRODUCTION}

Studying the organisms that make up the zooplankton-both temporary members, such as larvae, and species with completely planktonic life cycles, such as

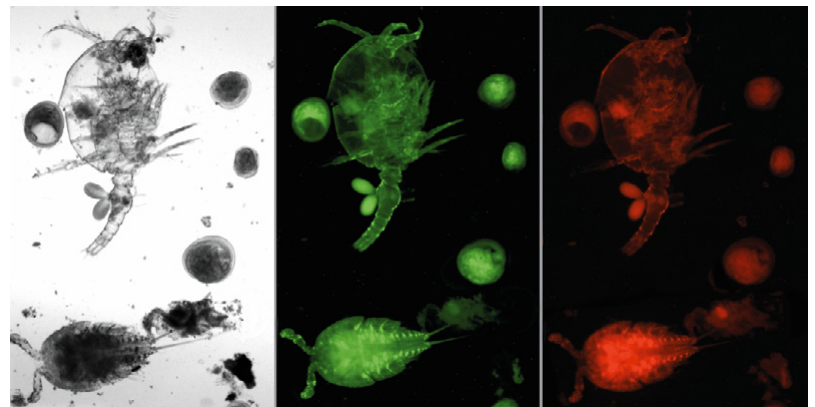

A green fluorescent DNA probe allows identification of mussel Mytilus galloprovincialis larvae in a plankton sample, despite autofluorescence in the plankton.

Image: Christine Henzler

some copepods - is a difficult enterprise. Understanding the distribution of even one species requires extensive plankton sampling, followed by painstaking manual sorting to identify and count the species of interest. However, for most taxa this extensive effort cannot adequately sort plankton to species level. An efficient method for accurately identifying and counting marine plankton would allow the scientific community to unlock the data stored in plankton collections and to embark on new projects that require large-scale plankton sampling. Efforts to sort historical plankton samples have already revealed organism responses to ocean climate cycles, including biological migrations in response to ocean warming (Beaugrand et al. 2009), oceanographic and biological responses to El Niño Southern Oscillation events (Longhurst 1967, 1998), and seasonal cycles in marine populations (Lindley \& Batten 2008). Additional studies of plankton composition could better identify trends and complexities in 
oceanographic and biological responses to climate variation and identify indicators of change (Beaugrand 2005). Such studies are limited, however, by the traditional method of sorting plankton samples using morphological characteristics, which is exceedingly-for rare species, prohibitively-time consuming. Additionally, identifying plankton by morphology is often only possible to a high taxonomic level, because both the morphological similarities between species and the morphological plasticity within a species can be large (Boidron-Metairon 1988, Levin 1990, Comtet et al. 2000). Morphological identification has been automated to some degree using image analysis techniques such as the Video Plankton Recorder (Davis et al. 1992, Davis et al. 1996, Culverhouse et al. 2006), but taxonomic resolution and identification accuracy are still too low for a wide range of scientific questions. Restricting studies to enumerating organisms at high taxonomic levels can confuse patterns of organism responses to ocean climate, as closely-related species can have remarkably different spawning periods and behavior (e.g. Becker et al. 2007). Thus, there has been a recent focus on developing molecular techniques to improve identification of larvae (Goffredi et al. 2006, Livi et al. 2006, Vadopalas et al. 2006, Le Goff-Vitry et al. 2007a, Pradillon et al. 2007). However, while these techniques more accurately identify targeted species in the plankton, they either sacrifice the ability to quantify plankton or still require time-consuming sorting.

Genetic methods reliably identify a given species, provided oligonucleotide primers or probes are rigorously designed and tested for cross-reactivity with related species. PCR assays that use species-specific primers can identify individual larvae or detect the presence of target species in bulk-extracted plankton samples (Hare et al. 2000, Morgan \& Rogers 2001, Deagle et al. 2003, Livi et al. 2006). These methods are efficient for identifying the presence or absence of species if DNA is batch-extracted from an entire plankton sample, but the number of targeted organisms present in a given sample cannot be quantified (Bilodeau et al. 1999, Morgan \& Rogers 2001). Organisms can be quantified if individually processed, but this is still extremely time-consuming, as it requires manually pre-sorting samples using morphological features and then extracting and amplifying the DNA of each individual. Quantitative PCR (qPCR) provides quantification of targeted species within a batch-processed plankton sample, but the accuracy of this method is complicated by a number of factors, including variation in the size of larvae (and hence gene copy number) and possible presence of PCR inhibitors in the plankton sample (Vadopalas et al. 2006, Pan et al. 2008).
While genetic approaches can improve the accuracy of plankton sorting, a new approach is needed to also increase the efficiency. Identifying marine bacteria and phytoplankton by hybridizing whole cells with taxon-specific, fluorescent-labeled oligonucleotide or antibody probes and then sorting using a flow cytometer (Collier 2000, for phytoplankton review; Gasol \& Del Giorgio 2000, for bacteria review) is a well-established procedure. The same whole-organism fluorescence in situ hybridization (FISH) technique has been used to identify marine larvae (Goffredi et al. 2006, Mountfort et al. 2007), but these are too large to be counted using traditional flow cytometers, and marine larvae labeled by this process must still be manually identified and counted. Fluorescent-labeled target species can be difficult to distinguish from autofluorescent plankton (C. Henzler pers. obs., Pradillon et al. 2007), although this can be addressed by in situ hybridization with a colored dye-labeled probe and sorting using a white-light microscope (Le Goff-Vitry et al. 2007a,b, Pradillon et al. 2007). Recently, a cell sorter that can handle organisms as large as marine copepods and invertebrate larvae has been developed. We have combined the FISH technique with cell sorting (CS) to identify and sort bivalve larvae from plankton samples. In addition to accurate identification of species of interest by in situ hybridization, this technique also resolves both the difficulty of distinguishing fluorescent-labeled plankton from autofluorescent plankton, and it reduces the time required to sort samples.

Plankton samples should ideally be collected in large volume and with high spatial and temporal resolution in order to capture the variability in diversity and abundance (Garland \& Zimmer 2002). Collecting large numbers and volume of plankton samples is relatively easy; processing these samples is only feasible with an accurate and efficient sorting method. The FISH-CS technique in the present study adapts proven methods for marking and sorting small marine organisms to larger zooplankton (bivalve larvae), and overcomes major challenges faced by previous methods for sorting large plankton. Our method allows rapid and accurate processing of the large number of plankton samples necessary to answer some longstanding questions about marine population dynamics and to elucidate patterns of biological response to changes in ocean climate.

\section{MATERIALS AND METHODS}

Sample collection. Plankton samples were collected by boat on 8 Jul 2009 using an $80 \mu \mathrm{m}$ plankton net towed horizontally at $40 \mathrm{~m}$ depth in $70 \mathrm{~m}$ deep water. A second plankton sample was collected on 14 Apr 2010, 
at the Goleta Pier by pumping water from a depth of 2 $\mathrm{m}$ for $15 \mathrm{~min}$ at a rate of $3.5 \mathrm{l} \mathrm{min}^{-1}$ and filtering it with an $80 \mu \mathrm{m}$ plankton net. Both samples were examined under a dissecting microscope and found to contain few if any bivalve larvae, although a variety of plankton organisms were present, including polychaete larvae, barnacle cyprids, copepods, amphipods, eggs and diatoms. Pure cultures of Mytilus galloprovincialis larvae at $10 \mathrm{~d}$ post-fertilization were shipped from Taylor Hatchery (Shelton, WA) and at $8 \mathrm{~d}$ post-fertilization from Whiskey Creek Hatchery (Tillamook, OR). Pure cultures of approximately 8 d old Crassostrea gigas larvae were shipped from Coast Seafoods (Bellevue, WA).

Sample preservation. Samples for FISH were preserved in saline ethanol following the modification of Miller \& Scholin (2000) (MSE; 70\% ethanol v/v, $375 \mathrm{mM} \mathrm{NaCl}, 2.5 \mathrm{mM}$ EDTA, $50 \mathrm{mM}$ Tris; $\mathrm{pH}$ 7.8). Hatchery samples of Mytilus galloprovincialis and Crassostrea gigas were shipped either damp or in seawater. From these samples live animals were selected for preservation in MSE. Plankton samples were immediately transferred to 11 Nalgene bottles and MSE was added at a ratio of 1:1 (v/v). On the same day as collection, large organisms were removed with a $1000 \mu \mathrm{m}$ sieve and the remaining sample was resuspended in $100 \%$ MSE.

Probe design. In situ hybridization protocols typically target $16 \mathrm{~S}$ (prokaryotes) or $18 \mathrm{~S}$ (eukaryotes) small subunit rRNA (ssu rRNA), as it is abundant in cells, is variable at genus or species levels for many taxa, and is an appropriate target for FISH probes for bivalves (Pernthaler et al. 2001, Le Goff-Vitry et al. $2007 \mathrm{a}$ and references therein). Probes were designed for 2 bivalve taxa, the Mytilus edulis/galloprovincialis/ trossulus species complex, and Musculista senhousia, targeting the $18 \mathrm{~S}$ ssu rRNA. Genbank $18 \mathrm{~S}$ sequences of $5 \mathrm{M}$. edulis, $2 \mathrm{M}$. galloprovincialis, $4 \mathrm{M}$. trossulus, 1 M. californianus and 1 Mytilus coruscus (GenBank accession numbers L33448, L33449, L33451-5, L2448990, AY527062, X59118, L78854 and EF613242) were aligned with $18 \mathrm{~S}$ sequences amplified from 5 additional $M$. californianus. An $1831 \mathrm{bp}$ segment of the $18 \mathrm{~S}$ gene was amplified for the $5 \mathrm{M}$. californianus individuals in 4 overlapping fragments using primers from the method of Turbeville et al. (1994). The position of each primer is from the human genome: Segment 1, 630 bp, forward: position 2-22, 5'-ACC TGG TTG ATC CTG CCA-3', reverse: 632-615, 5'-GWA TTA CCG CGC GGC KGC TG-3'; Segment 2, 1200 bp, forward: 2-22, 5'-ACC TGG TTG ATC CTG CCA-3', reverse: 12011187, 5'-ATT CTT TRA GTT TC-3'; Segment 3, 1320 bp, forward: 437-447, 5'-CGG AGA RGG AGC CTG AGA, reverse: 1708-1692, 5'-ACG GGC GGT GTG TRC-3'; and Segment 4, 840 bp, forward: 1024-1038, 5'-ATC AAG AAC GAA AGT-3', reverse: 1865-1847,
5'-TGA TCC ATC TGC AGG TTC-3'. PCR products were purified using the Bioneer AccuPrep PCR Purification Kit, and purified PCR products were sequenced in forward and reverse directions by the University of Washington high-throughput sequencing facility. From these aligned sequences, an 18 nucleotide probe targeting the $M$. edulis/galloprovincialis/trossulus species complex (EGT probe) was designed by eye, differing from all non-target taxa by 3 to 4 nucleotides. An 18 base probe targeting Musculista senhousia (MUSC probe) and differing by 5 or more nucleotides from non-target taxa was designed using the program ARB (v. 07.12.07org; Ludwig et al. 2004) and a database of mollusc $18 \mathrm{~S}$ sequences. A mollusc database was constructed using the Silva comprehensive RNA ribosomal database (www.arb-silva.de/) search tool to download all full-length, high-quality $18 \mathrm{~S}$ mollusc sequences (sequence, alignment and pintail qualities greater than $75 \%$ ). This database was imported into $\mathrm{ARB}$ and the 'probe design' function was used to search for 18 base probes targeting $M$. senhousia.

Dot blot hybridization. The specificity of the EGT and MUSC probes was tested using dot blot hybridization following the procedure of Le Goff-Vitry et al. (2007a). DNA was extracted from 65 individuals representing 10 different bivalve species found in southern California waters: 10 Mytilus galloprovincialis, $10 \mathrm{M}$. trossulus, $5 \mathrm{M}$. edulis, $10 \mathrm{M}$. californianus, $10 \mathrm{Mus}-$ culista senhousia, 8 Septifer bifurcatus, 5 Modiolus sacculifer, 3 Adula diegensis, 2 Ruditapes philippanarum and 2 Crassostrea gigas. A section of the $18 \mathrm{~S}$ gene was PCR-amplified using the primers 5'-ACC TGG TTG ATC CTG CCA-3' \& 5'-ACG GGC GGT GTG TRC-3' (Turbeville et al. 1994) and then purified using Qiagen (Valencia) or Bioneer (Alameda) PCR purification kits. Approximately $1000 \mathrm{ng}$ of 18S DNA from each individual was applied to each of $2 \mathrm{~N}+$ Hybond membranes (GE Life Sciences), and bound to the membrane by UV crosslinking at $70000 \mathrm{~kJ} \mathrm{~cm}^{-2}$. Probe preparation and dot blot hybridization were carried out using the Alk Phos Direct Labeling kit with CDP-Star Detection reagent (GE Life Sciences) and following the modified protocol for oligonucleotide probes. Briefly, probes were prepared from unlabeled oligonucleotides corresponding to the $2 \mathrm{FISH}$ probes by crosslinking alkaline phosphatase to each oligonucleotide (by incubating at $37^{\circ} \mathrm{C}$ for $5 \mathrm{~h}$ ). Blots were prehybridized in $25 \mathrm{ml}$ of hybridization buffer at $37^{\circ} \mathrm{C}$ for $15 \mathrm{~min}$, then a labeled probe was added to each blot (16 ng probe $\mathrm{ml}^{-1}$ hybridization buffer) and blots were hybridized overnight. Hybridization buffer was prepared using the pre-mixed hybridization buffer solution in the AlkPhos Direct Labeling Kit (Amersham) with $\mathrm{NaCl}$ added to a $0.5 \mathrm{M}$ concentration and $4 \%$ $(\mathrm{w} / \mathrm{v})$ of the blocking reagent provided in the kit. Blots 
were washed twice in a primary wash buffer (2 M urea, $0.1 \%$ sodium dodecyl sulphate [SDS], $50 \mathrm{mM}$ sodium phosphate $\mathrm{pH} 7.0,150 \mathrm{mM} \mathrm{NaCl}, 1 \mathrm{mM} \mathrm{MgCl}_{2}$, and $0.2 \%$ blocking reagent) for $10 \mathrm{~min}$ at $37^{\circ} \mathrm{C}$ and twice in secondary wash buffer $(50 \mathrm{mM}$ Tris, $100 \mathrm{mM} \mathrm{NaCl}$, $2 \mathrm{mM} \mathrm{MgCl}_{2}, \mathrm{pH}$ 10.0) for $5 \mathrm{~min}$ at room temperature. Then, $3.4 \mathrm{ml}\left(40 \mu \mathrm{cm}^{-2}\right)$ of CDP-Star detection reagent was added to each blot, and blots were allowed to incubate at room temperature for $5 \mathrm{~min}$. Blots were visualized with a 10 to $15 \mathrm{~min}$ exposure using a Versadoc imaging system (Model 1000, BioRad).

Fluorescence in situ hybridization. FISH was performed with the EGT probe, but not the MUSC probe, since a pure culture of Musculista senhousia was not available for testing. FISH with the EGT probe was performed on 5 sets of samples with corresponding controls: (1) hatchery-raised mussels, Mytilus galloprovincialis, (2) hatchery-raised oysters, Crassostrea gigas, (3) plankton, (4) mussels and oysters ('mussel/oyster') and (5) mussels and plankton ('mussel/plankton'). Probes were ordered from MWG Operon with Alexa Fluor 488 (green) or TET (yellow) fluorescent dyes attached to the $5^{\prime}$ end. The COPAS cell sorter (Union Biometrica) can detect red, yellow and green fluorescence, so up to 3 colored dyes can be used to label probes; in the present study we tested 2. Samples (several thousand plankton organisms and/or larvae) were added to $2 \mathrm{ml}$ microcentrifuge tubes and centrifuged at $3300 \times g$ for $3 \mathrm{~min}$. Excess MSE was removed until the final volume of sample and MSE was $500 \mu \mathrm{l}$. Samples were permeabilized using the method of Pradillon et al. (2007), by adding $12 \mathrm{~N} \mathrm{HCl} \mathrm{(1 \%} \mathrm{v/v)} \mathrm{and}$ agitating at room temperature for $10 \mathrm{~min}$. The FISH protocol was adapted from Goffredi et al. (2006) with changes made to improve the signal and reduce nonspecific binding. Samples were rinsed with $500 \mu \mathrm{l}$ of freshly prepared $5 \times \mathrm{SET}$ hybridization buffer $(5 \times \mathrm{SET}$, $0.1 \% \mathrm{v} / \mathrm{v}$, IGEPAL-CA630, $25 \mu \mathrm{g} \mathrm{ml}^{-1}$ polyadenylic acid; Miller \& Scholin 1996) pre-warmed to the hybridization temperature of $55^{\circ} \mathrm{C}$ ( 5 to $7^{\circ} \mathrm{C}$ below the probe melting temperature), and centrifuged $(3300 \times g, 3 \mathrm{~min})$. Supernatant was removed and the samples were resuspended in pre-warmed $5 \times$ SET hybridization buffer to a final volume of $500 \mu \mathrm{l}$. Samples were prehybridized at $55^{\circ} \mathrm{C}$ for $1 \mathrm{~h}$ before the probe was added. Varying concentrations of probe (green, Alexa Fluor 488-labeled probe: 1.5, 2.5

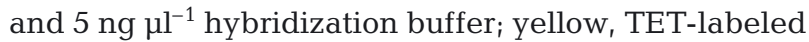
probe: 2.5 and $5 \mathrm{ng}^{-1} \mathrm{l}^{-1}$ hybridization buffer) were tested for mixed mussel and plankton samples to maximize the signal-to-noise ratio. For the mussel/oyster samples, the green-labeled probe was used at a concentration of $2.5 \mathrm{ng} \mathrm{l}^{-1}$. Probe was added to each sample and allowed to hybridize with the sample for $3 \mathrm{~h}$ with gentle agitation. Samples were centrifuged ( $3300 \times g, 3 \mathrm{~min})$, and the hybridization buffer and probe were removed. To eliminate non-specific binding, samples were washed 3 times in
$500 \mu \mathrm{l} 1 \times \mathrm{SET}$ buffer at $55^{\circ} \mathrm{C}$ for $10 \mathrm{~min}$, with gentle agitation; samples were centrifuged $(3300 \times g, 3 \mathrm{~min})$ and the supernatant was removed after each wash. Samples were then resuspended in $500 \mu$ l of hybridization buffer and stored in the dark until sorting. Immediately prior to sorting, each sample was diluted in $\sim 20 \mathrm{ml}$ of distilled water. Controls underwent the same permeabilization, prehybridization, hybridization and wash procedures as the experimental samples, except that no probe was added in the hybridization step.

Microscope imaging. Images of samples hybridized with the Alexa Fluor 488-labeled EGT probe (2.5 ng $\mathrm{ul}^{-1}$ concentration for hybridization) and corresponding control samples were taken using an Olympus BX60 microscope. White-light and fluorescent images (using a fluorescein filter) were taken of each sample at $100 \times$ magnification.

Cell sorting. Larvae were sorted using a COPAS Plus cell sorter (Union Biometrica) with a $1 \times 1 \mathrm{~mm}$ square flow cell and $488 \mathrm{~nm}$ laser. The cell sorter records 5 parameters for every particle, including time of flight past the laser (a measure of size), extinction (a measure of optical density) and fluorescence in the red (575 to $595 \mathrm{~nm}$ ), yellow (532.5 to $557.5 \mathrm{~nm}$ ) and green (498.5 to $521.5 \mathrm{~nm}$ ) parts of the spectrum. All FISH samples (hatchery-raised mussels, hatchery-raised oysters, plankton, mussel/oyster, and mussel/plankton) and their corresponding controls underwent cell sorting.

DNA extraction and PCR identification of sorted mussel larvae. To assess false positive and false negatives in the Alexa Fluor 488-probed (green) mussel/ plankton sample, mussel larvae were sorted into a $50 \mathrm{ml}$ centrifuge tube. Sorting parameters were chosen to select particles having more green:yellow fluorescence than control samples (this ratio was constant among all control runs, both mussel/plankton and mussel/oyster). Two sets of sorting parameters were used; one that included particles having only slightly greater green: yellow fluorescence than control particles, and one where a higher threshold of green:yellow fluorescence was needed for a particle to be selected. To determine the number of false positives (particles that fell within the sorting parameters but were not actually Mytilus galloprovincialis), 96 of the particles sorted under each of these sorting parameter settings were each hand-placed into a well of a 96-well plate. To determine the number of false negatives, the non-sorted 'waste' plankton was collected, and all bivalve larvae were removed by hand and placed individually into PCR tubes. Larvae were extracted using the simple DNA extraction protocol of Gloor et al. (1993): $50 \mu \mathrm{l}$ of squishing buffer was added to each well, and plates were incubated at $37^{\circ} \mathrm{C}$ for $30 \mathrm{~min}$ and $95^{\circ} \mathrm{C}$ for $2 \mathrm{~min} ; 3 \mu \mathrm{l}$ were then used directly in a $15 \mu \mathrm{l}$ PCR reaction with Mytilus spp. adhesive protein gene primers (Inoue et al. 1995). Then, $10 \mu \mathrm{l}$ of each PCR reac- 
tion was run on an agarose gel; the presence or absence of a $126 \mathrm{bp}$ band was scored as presence or absence of M. galloprovincialis. Samples for this experiment were sorted into a single container and then placed by hand into plates because, while the cell sorter can dispense larvae automatically into 96-well plates, the cell sorter does not sort particles while it is moving between wells of a plate. Thus, any larva that meets the sorting criteria but is being scanned while the sorter is moving between wells of a plate is diverted to the waste, and will appear to be a false negative if the waste container is examined. However, data is gathered on these particles, and the datafile includes records of how many particles met the sorting criteria but were not dispensed for this reason; but since they are all diverted to a single waste container, there is no way to assess which of the particles meeting the sorting criteria were not sorted due to mechanical limitations, and which were false negatives. For field-collected samples, once the incidence of false negatives is evaluated and considered acceptable, samples can be machine-sorted into a 96-well plate; all samples that meet the sorting criteria will be cataloged and can be counted, but some will be diverted to the waste container.

For the Alexa Fluor 488-probed mussel/oyster sample, some of the mussel larvae were machine-sorted, 1 larva per well, into two 96-well plates. Sorting parameters were determined from control samples (as for the mussel/plankton samples). Each larva was dispensed in a $15 \mu \mathrm{l}$ drop of liquid that was a combination of cell sorter sheath fluid and the liquid in which the sample was suspended (largely distilled water with a small amount of hybridization buffer). The number of larvae per well was verified using a dissecting microscope. Larvae in the plates underwent the same PCR assay as larvae in the mussel/plankton samples: they were extracted using the simple DNA extraction protocol of Gloor et al. (1993) with the squishing buffer modified to compensate for the $15 \mu$ lalready in each well (for a total volume of $50 \mu \mathrm{l}$ ), and $3 \mu \mathrm{l}$ were then used directly in a PCR reaction with Mytilus adhesive protein gene primers (Inoue et al. 1995) to verify that the sorted larvae were M. galloprovincialis and not Crassostrea gigas.

\section{RESULTS}

\section{Sample preservation, probe development and testing}

Samples freshly preserved in 100\% MSE maintained their morphology and Mytilus galloprovincialis larvae were sufficiently hybridized by the EGT probe to be distinguished from other plankton organisms, even after several months of preservation. The probe for Mytilus edulis/galloprovincialis/trossulus (EGT) is 5'-
AGG TCA GGA GCA GGC AGT -3' (melting temperature, $\mathrm{T}_{\mathrm{m}}=62.2^{\circ} \mathrm{C}$ ), and for Musculista senhousia (MUSC) is 5'- GTA AAC CGA CGG TGT CGG -3' $\left(\mathrm{T}_{\mathrm{m}}=62.2^{\circ} \mathrm{C}\right)$. Results of the dot blot hybridizations are shown in Fig. 1, and show that the EGT and MUSC probes are specific to their target taxa. FISH tests with cultured larvae and plankton samples showed that the EGT probe hybridized to the target species $M$. galloprovincialis, but did not hybridize non-specifically to the plankton sample or to C. gigas (Fig. 2). The Alexa Fluor 488-labeled probe worked well at all concentra-

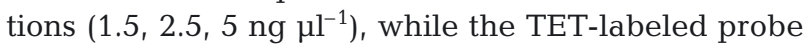

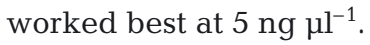

\section{Cell sorting}

As expected, plankton samples had a wide range of particle sizes and autofluorescence (Fig. 3A,C). When the sample of mixed hatchery-raised mussel larvae and plankton was probed with the Alexa Fluor 488labeled (green) probe, the autofluorescence of some of the plankton sample was as bright as that of the probed larvae (Fig. 3B). Normally, such autofluorescence could compromise the effectiveness of labeling techniques by yielding false positives. However, natural autofluorescence of preserved samples showed a convenient pattern that can be used to resolve its confounding effects. The ratio of autofluorescence in any 2 of the 3 colors detected by the cell sorter (red, 575 to $595 \mathrm{~nm}$; yellow, 532.5 to $557.5 \mathrm{~nm}$; and green, 498.5 to $521.5 \mathrm{~nm}$ ) is remarkably constant among particles in a plankton sample and among plankton samples, regardless of size or type of particle (larvae, detritus, etc.). When fluorescence data for any 2 colors is plotted, the particles in control plankton and/or larvae samples fall tightly on a line; this ratio does not seem to change among plankton samples or with the length of time a particular sample is preserved in modified salt ethanol (data for 2 plankton samples and 2 batches of mussel larvae illustrate this in Fig. 3C). Probing with a fluorescent dye increased the fluorescence of the target larvae only in the dye's part of the spectrum (e.g. green for Alexa Fluor 488, yellow for TET) while not correspondingly increasing target larvae fluorescence in other parts of the spectrum. This changed the ratio of fluorescence brightness between colors in target larvae, but not non-target taxa. Probes labeled with Alexa Fluor 488 or with TET allowed target mussel larvae to be differentiated from the plankton sample (Figs. 3D \& 4B,4C) or oyster larvae (data not shown). To more easily differentiate probed mussel larvae from unprobed plankton for sorting, we adjusted the compensation settings in the COPAS software to remove the green autofluorescence signal (Fig. 4B,C). 


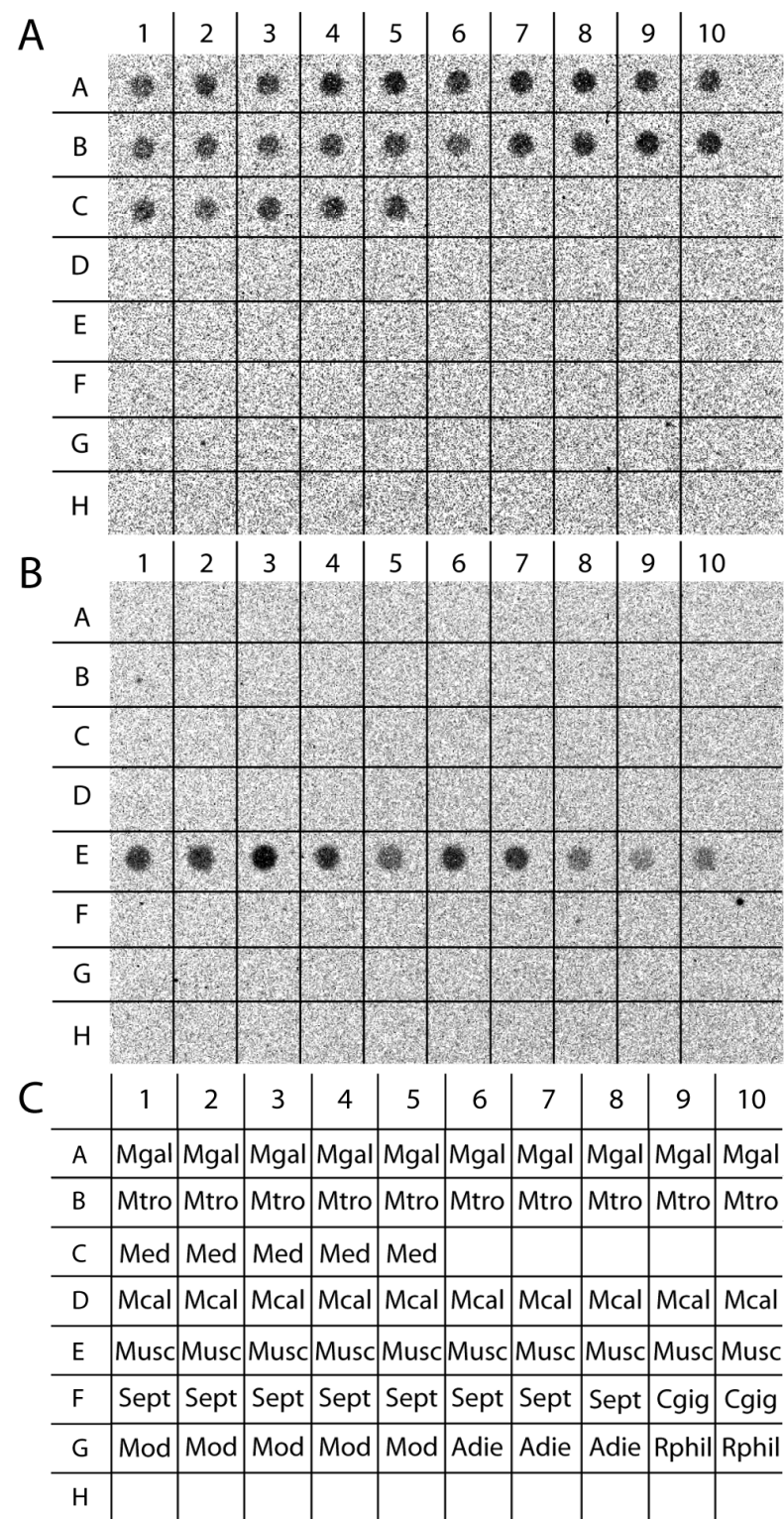

Fig. 1. Dot blot probe specificity tests. Dot blots with (A) Mytilus edulis/galloprovincialis/trossulus probe, and (B) Musculista senhousia probe. (C) Layout of dot blots: $\mathrm{Mgal}=M$. galloprovincialis, $\mathrm{Mtro}=M$. trossulus, $\mathrm{Med}=$ M. edulis, Mcal $=M$. californianus, Musc $=M$. senhousia, Sept $=$ Septifer bifurcatus, $\mathrm{Mod}=$ Modiolus sacculifer, Adie $=$ Adula diegensis, Cgig $=$ Crassostrea gigas, Rphil = Ruditapes philippanarum

\section{DNA extraction and PCR amplification of sorted mussel larvae}

In the first test of false positive and false negative rates, more inclusive sorting parameters were used (Fig. 4). The COPAS sorter scanned 1501 particles (larvae, detritus, etc.) of a mixed $M$. galloprovincialis larvae/plankton sample after FISH, using the EGT probe. A total of 593 particles met the sorting criteria
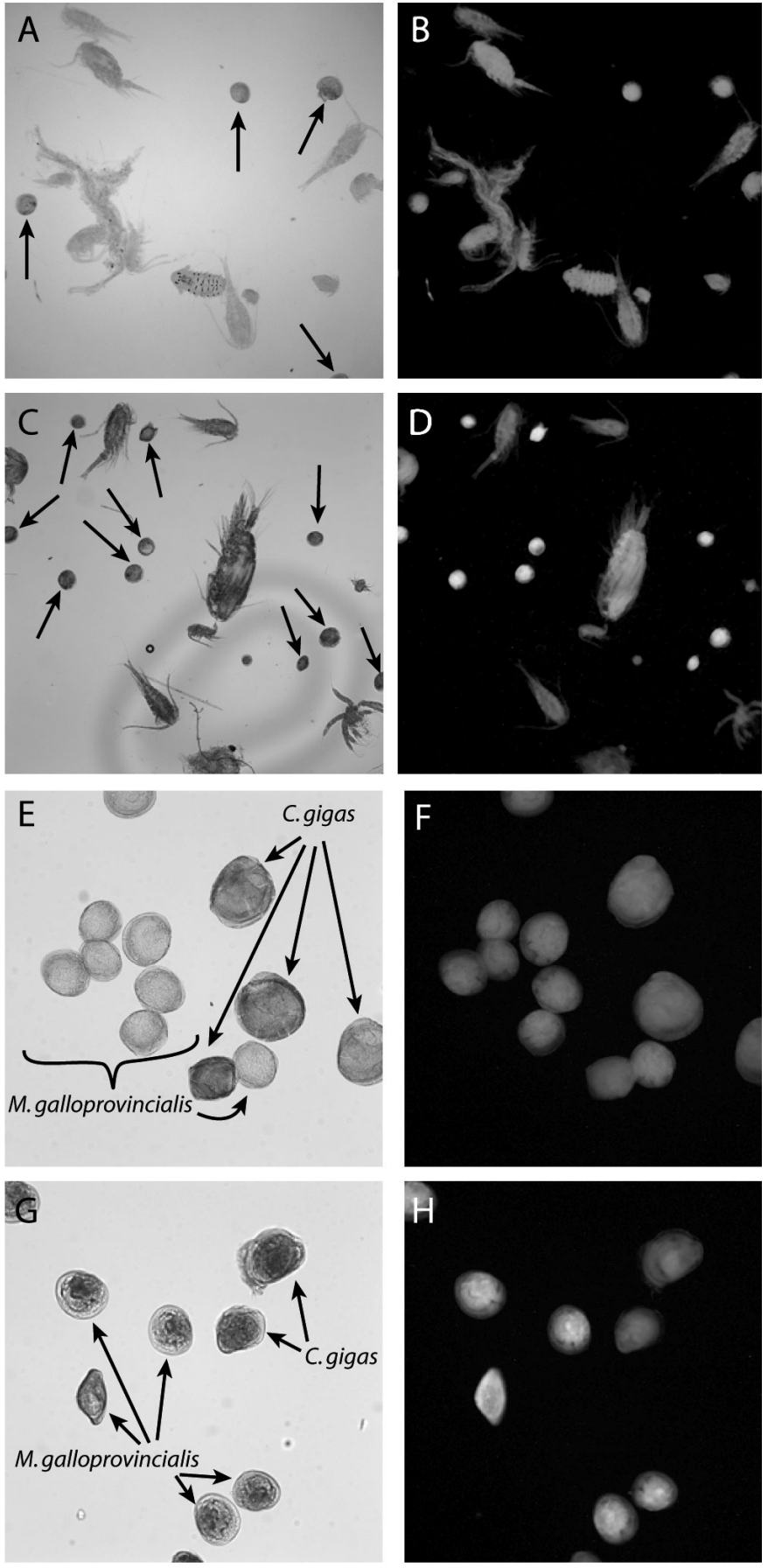

Fig. 2. (A-D) Mytilus galloprovincialis larvae and plankton sample, (E-H) Mytilus galloprovincialis \& Crassostrea gigas larvae. (A) White light and (B) fluorescein filter of control treatment showing autofluorescence; (C) white light and (D) fluorescent image under fluorescein filter after FISH with Alexa Fluor 488 EGT probe. (E) White light and (F) fluorescent image under fluorescein filter of control treatment; (G) white light and $(\mathrm{H})$ fluorescent image after FISH with Alexa Fluor 488 EGT probe. Arrows in $(A, C)$ denote the 4 and 10 M. galloprovincialis larvae, respectively, in each image. (A-D) are scaled to $\sim 10 \times$ magnification, and $(\mathrm{E}-\mathrm{H})$ are scaled to $\sim 25 \times$ magnification 

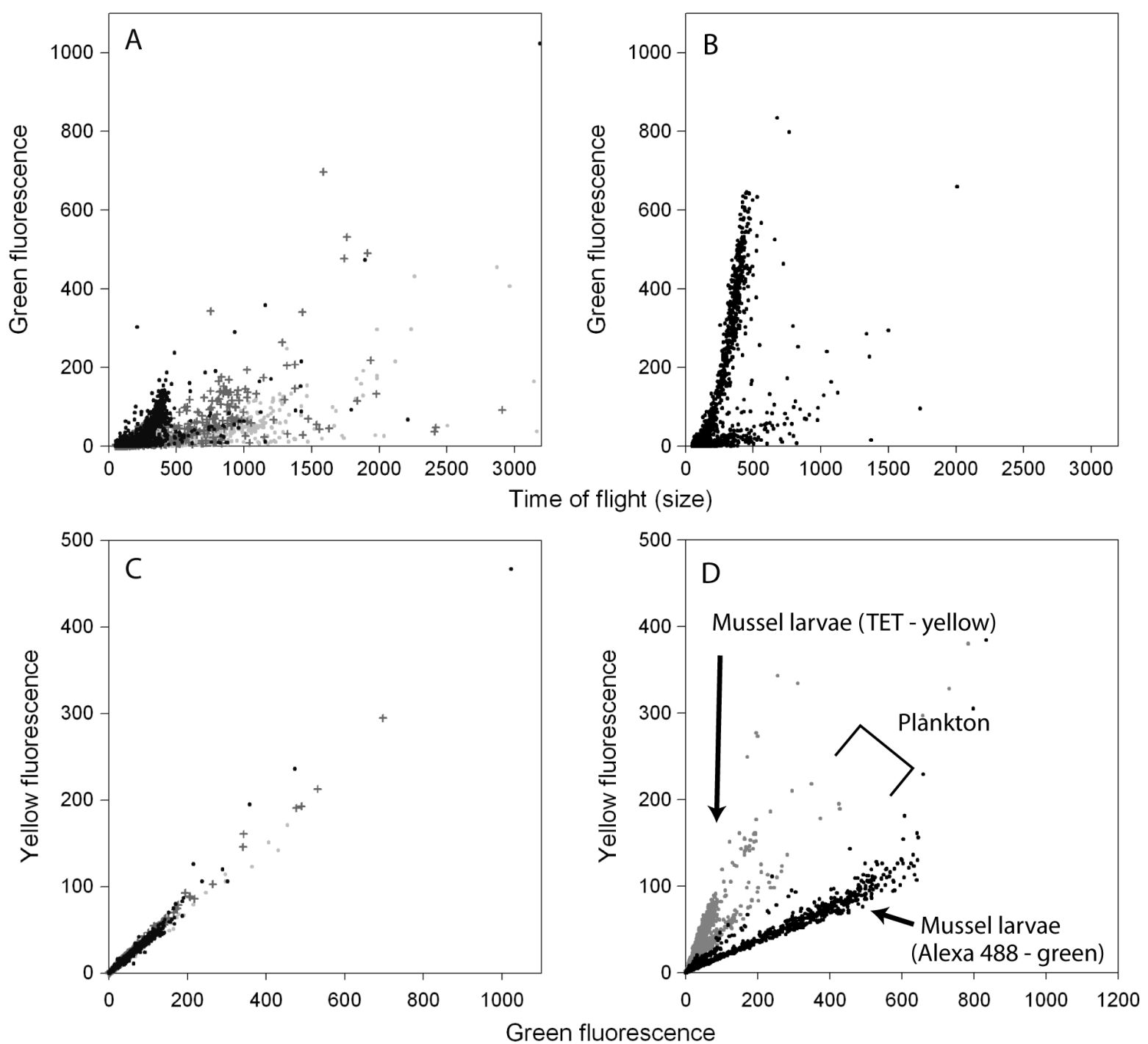

Fig. 3. Cell sorter results. (A,B) Size versus green fluorescence, and $(C, D)$ green versus yellow fluorescence for $(A, C) 3$ control samples of mixed mussel larvae and plankton, including the control corresponding to the FISH samples in (B) \& (D), respectively (black), overlaying plankton and mussel control samples from a different sampling date (June/July 2009) that underwent cell sorting within 1 mo (dark gray, +) and 6 mo (light gray) of preservation in modified salt ethanol; and for (B) mussel larvae and plankton after FISH with Alexa Fluor 488 EGT probe and (D) mussel larvae and plankton after FISH with Alexa Fluor 488 EGT probe (black) and after FISH with TET EGT probe (gray). Note that in (D), while plankton from both samples stay in the same position as the control sample in (C), mussel larvae hybridized with the Alexa Fluor 488 EGT probe have more green fluorescence and mussel larvae hybridized with the TET EGT probe have more yellow fluorescence than the plankton in the samples

(heightened green fluorescence; Fig. 4B). DNA was extracted from 96 of the sorted individuals to confirm their identity by PCR assay with the Mytilus adhesive protein primers of Inoue et al. (1995). A total of 85 of these 96 larvae were confirmed to be M. galloprovincialis, an $11.5 \%$ false positive rate. Of the 908 particles that did not meet the sorting criteria, 3 appeared to be bivalves and of these only one was confirmed to be $M$. galloprovincialis, for a false negative rate of $0.11 \%$. For the second test, the sorting parameters were adjusted to increase the minimum green fluorescence required for sorting (to attempt to reduce the false positive rate). Of the 1696 particles scanned by the cell sorter, 501 met the sorting criteria, and 94 of a subset of 96 individuals were confirmed to be $M$. galloprovincialis, yielding a false positive rate of $2.1 \%$. Of the 1195 particles that did not meet sorting criteria, 22 appeared to be bivalves and underwent PCR assay, and 12 of these were confirmed to be $M$. galloprovincialis for a $1.0 \%$ false negative rate.

Of 112 larvae that FISH-CS identified as Mytilus galloprovincialis and sorted from a mixed oyster (Cras- 

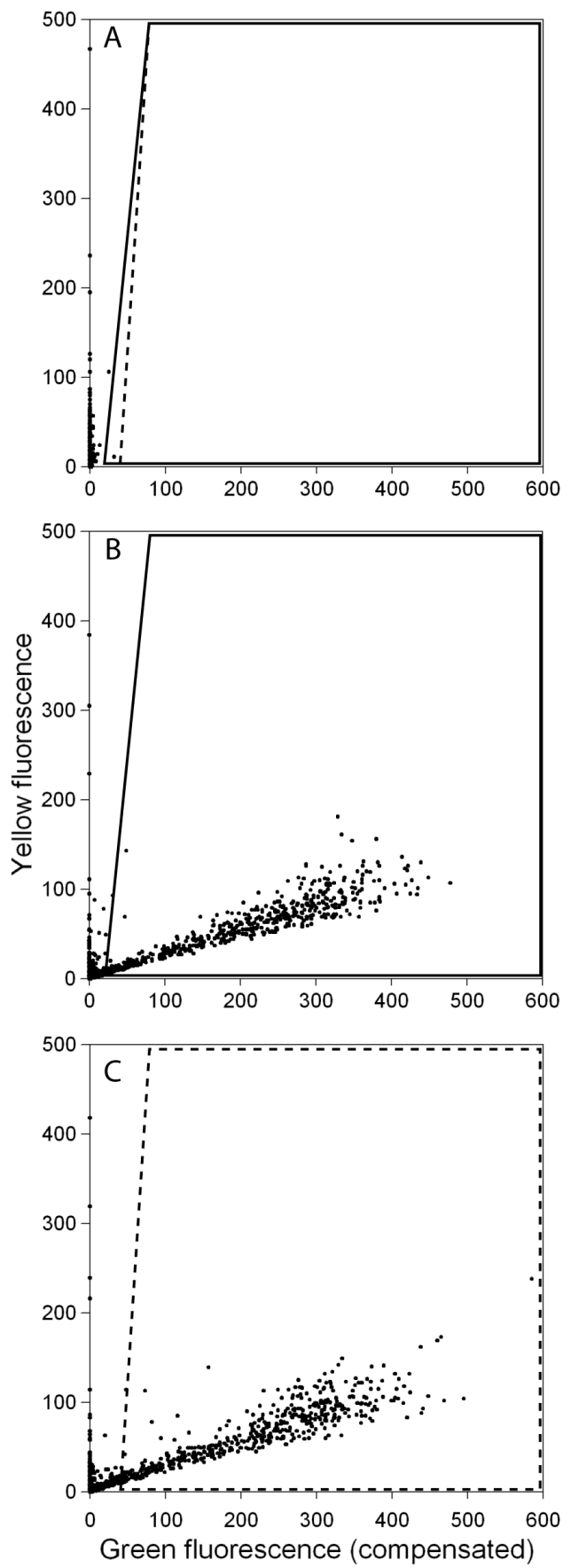

Fig. 4. Cell sorter results plotted after the green autofluorescence has been removed by compensation settings in the cell sorter's software. (A) Control mixed mussel larvae and plankton with the 2 sort regions (black and dashed-line trapezoids) used in (B) \& (C), respectively, superimposed for reference; $(\mathrm{B}, \mathrm{C})$ mussels/plankton after FISH with Alexa Fluor 488 EGT probe. (B) Black data in Fig. 3D replotted after compensation; this sample underwent sorting with the first, most inclusive sorting parameters (all particles within the black trapezoids were sorted). (C) Sorting parameters were adjusted to accept higher levels of green fluroescence than in (B) (all particles within the dashed line were sorted). In (B) \& (C), the polygon shows the area used to sort the green-dye-probed mussel larvae from the sample sostrea gigas) and M. galloprovincialis sample into 96-well plates, all were confirmed to be M. galloprovincialis by PCR assay with the Mytilus adhesive protein primers of Inoue et al. (1995).

\section{DISCUSSION}

The FISH-CS method accurately identifies marine larvae, and provides a novel method for rapidly counting and sorting species from diverse plankton samples. The method can count up to 3 taxa simultaneously, and allows 1 target taxon at a time to be sorted from the sample for further analysis. This is the first automated application of the FISH-CS technique to zooplankton, and we demonstrate the efficacy of this technique for identifying and sorting plankton samples.

\section{Sample preservation}

For FISH-CS, samples must be properly preserved to maintain target rRNA. Probes did not successfully hybridize to mussel larvae ( $M$. galloprovincialis) that were shipped overnight from a hatchery but died before preservation in MSE (data not shown), while mussel larvae in the same shipment that were preserved when alive hybridized as expected. This indicates that the target rRNA degrades rapidly after animals die and care should be taken to ensure that plankton organisms are still alive when preserved. Pradillon et al. (2007) effectively hybridized probes to marine larvae preserved in $70 \%$ ethanol in seawater, but in preliminary analyses, we found that the probe did not hybridize to mussel samples preserved in $95 \%$ ethanol. Adapting the method presented here to samples stored in alternative buffers such as $95 \%$ ethanol or formalin is an obvious next step that would allow efficient processing of historical samples housed in plankton collections.

\section{Permeabilization}

Applying an acid treatment to permeablize samples increased hybridization and did not degrade samples. Mussel larvae that were treated with $1 \%$ (v/v) $12 \mathrm{~N}$ $\mathrm{HCl}$ before hybridization had greater hybridization efficiency compared to mussel larvae that were not acid treated (data not shown), confirming the results of Pradillon et al. (2007). Acid treatment weakened mussel shells relative to untreated larvae (more shell cracking was observed in acid-treated larvae viewed under the microscope), but larvae remained intact through FISH and cell sorting. Acid treatment did not 
seem to damage larvae of other taxa in plankton samples, which were observed under the microscope and compared to untreated plankton. Because different life history stages and taxa require varying levels of permeabilization, a single permeabilization treatment applied uniformly to a plankton sample may be too strong for some larvae and not strong enough for others, causing false negatives (not enough acid leaves larvae impermeable to the probe and too much acid results in tissue loss and no hybridization; Pradillon et al. 2007). Further testing of multiple mussel larval lifehistory stages is necessary to evaluate the effect of this permeabilization procedure; however, the treatment used in the present study was enough to permeabilize bivalve larvae and did not cause structural damage to more delicate urchin larvae at either prism or 4-arm developmental stages (data not shown).

\section{Probe gene targets}

Our current method targets 18S ssu rRNA, the same target widely used in similar FISH cell-sorting techniques for identifying such taxa as marine bacteria (where the prokaryotic ssu rRNA, 16S, is the target; Pernthaler et al. 2001) and other marine invertebrates (Goffredi et al. 2006, Le Goff-Vitry et al. 2007a). While in many taxa a short oligonucleotide probe targeting $18 \mathrm{~S}$ can differentiate species, in other groups $18 \mathrm{~S}$ is not variable enough to allow for more than a single base pair difference between species in a 20 base pair oligonucleotide probe. In future experiments, we will investigate whether other, high-copy genes can be used as targets for the probe. Initial experiments testing whether the mitochondrial cytochrome $c$ oxidase subunit I (COI) gene could be used as a probe target were unsuccessful (data not shown) but warrant further testing, as this is the primary gene for differentiating species in the Barcode of Life project (Hebert et al. 2003).

\section{Probe quantity and hybridization conditions}

Hybridizing samples with 1.5 ng Alexa Fluor 488labeled probe or $5 \mathrm{ng}$ TET-labeled probe per $\mu \mathrm{l}$ of $25 \times$ SET hybridization buffer for $3 \mathrm{~h}$ optimally labeled targeted mussels. Other studies that have applied in situ hybridization to marine larvae use between 1 and $5 \mathrm{ng}$ of probe per $\mu \mathrm{l}$ of hybridization buffer (Miller \& Scholin 1996, 2000, Goffredi et al. 2006, Le Goff-Vitry et al. 2007a). We tested 1.5, 2.5 and $5 \mathrm{ng}^{-1} \mathrm{l}^{-1}$ Alexa Fluor 488-labeled probe with similar results (data not shown), and so use 1.5 or $2.5 \mathrm{ng} \mathrm{\mu l}^{-1}$ to reduce costs. Hybridization times in similar studies vary between 45 min (Gof- fredi et al. 2006) and overnight (Le Goff-Vitry et al. 2007a, Pradillon et al. 2007). We tested 1 h, 3 h, and overnight hybridizations and found that hybridization efficiency was better at $3 \mathrm{~h}$ than $1 \mathrm{~h}$ without increasing non-specific binding, and that overnight hybridizations did not substantially increase probe binding (data not shown).

Hybridization specificity was achieved by designing probes that differed by at least 3 to 4 bases from other taxa, minimizing the chance of probes binding to non-target species. In the event that probes for other taxa cannot be designed with the same level of differentiation, probe specificity may be achieved by raising the hybridization temperature or via the addition of varying amounts of formamide to the hybridization buffer.

\section{Washes}

We found that multiple stringent washes were necessary to remove non-specific binding of probe to plankton samples. We initially washed hybridized samples for 5 min with $5 \times$ SET buffer at room temperature, and found that while the targeted mussels were more fluorescent than the plankton sample, the plankton sample was substantially more fluorescent than the control plankton sample which was not exposed to a fluorescent probe. We were able to remove non-specific probe binding almost completely by increasing the stringency of the wash buffer to $1 \times$ SET and increasing the number, time and temperature of washes to three 10 min washes at the hybridization temperature. This was somewhat more stringent than other protocols (e.g. Miller \& Scholin 2000, Groben \& Medlin 2005, Goffredi et al. 2006), but was necessary to fully remove non-specific binding. The requisite time, number and stringency of washes may depend on the binding efficiency and specificity of each individual probe.

\section{Cell sorting}

The large-flow cell COPAS Plus cell sorter provides an efficient method for sorting marine larvae (and other types of plankton) to species level. The cell sorter allows us to take advantage of the constant ratio between green and yellow autofluorescence in plankton samples, mitigating the difficulties of using FISH on plankton samples that have unpredictable autofluorescence. The speed of sorting can be adjusted, but between 5 and 10 particles sorted $\mathrm{s}^{-1}$ is ideal for allowing the COPAS to accurately scan and sort samples, while still allowing a sample to be run in a reasonable 
length of time ( $\sim 5$ to $10 \mathrm{~min})$. The $1 \mathrm{~mm}$ diameter flow cell of the COPAS Plus limits the size of the larvae that can be sorted with this technique. COPAS XL (Union Biometrica) has a flow cell diameter of $2 \mathrm{~mm}$, allowing larger particles to be sorted, but this still excludes most fish larvae, the late-stage larvae of some invertebrate taxa (e.g. crab megalopae) and other large zooplankton (e.g. some copepods). While FISH can be used to identify these taxa, they have to be manually sorted under a fluorescence microscope, making other identification methods such as in situ hybridization with colored dyes equivalent or preferable.

After the FISH-CS procedure, larvae still contain usable DNA that can be easily extracted, allowing for high-throughput genetic analyses on marine larvae and plankton. Target species can be rapidly identified, sorted from a plankton sample, and distributed into a 96-well plate. Our results show that a nuclear gene can be amplified from a fraction (usually $3 \mu \mathrm{l}$ of $50 \mu \mathrm{l}$ total) of the DNA extracted from a single larva that has undergone FISH-CS.

The cell sorter can detect 3 colors, so up to 3 different probes can be hybridized to different taxa in a sample allowing the cell sorter to count 3 types of larvae at one time. Permeabilization and FISH protocols may need to be optimized for individual species/probe combinations and could limit multiplexing; however, if similar types of larvae (e.g. different bivalve species) are probed at the same time using probes with similar mismatches to non-target taxa, multiplexing is more likely to be successful. Further research is needed to test multiplexing in different types of species. Unlike counting, sorting of probed larvae is based on a single set of criteria, so only one type of probed larva can be sorted from a sample for verification or additional analyses. However, the sample is retained after counting, and could be re-sorted for a different probe. The method may also be extended so that following a round of FISH-CS, the unsorted portion of the sample is retrieved from the waste container and re-probed for a different set of larval species and re-counted and sorted. Using such techniques, large numbers of species could be counted and sorted from the same plankton samples.

FISH-CS requires $1 \mathrm{~h}$ of pre-hybridization and $3 \mathrm{~h}$ of hybridization, however the actual hands-on time is quite short. Furthermore, multiple samples can undergo FISH simultaneously, increasing the efficiency of the method. FISH-CS is most efficient when only a single taxon needs to be sorted from a sample, since samples need only be run once through the cell sorter. We have only presented data for small $(500 \mu l)$ hybridization volumes, but preliminary data suggest that the protocol can easily be scaled up to $50 \mathrm{ml}$ or larger volumes. Given the speed of sorting, a single person could sort a single taxon of larvae from at least 10 plankton samples in $8 \mathrm{~h}$, with much of that time taken by incubations.

While a specialized cell sorter is needed to process samples, the cost of FISH per sample is quite low and dominated by the cost of the fluorescent probes. We used Alexa Fluor 488 instead of the much cheaper fluorescein because it provided a much better signalto-noise ratio. Despite this, the cost per sample is similar to or cheaper than other ISH protocols. The cost of FISH with an Alexa Fluor 488 probe (using $1.5 \mathrm{ng} \mathrm{ul}^{-1}$ ) was $\sim$ US $\$ 1.50$ for the $500 \mu$ l scale reaction $(\geq 1500$ particles), while with the TET probe it was $\sim$ US $\$ 0.40$. This compares favorably with the cost of ISH with horseradish peroxidase or digoxygenin probes; Pradillon et al. (2007) found that up to several hundred larvae could be processed using these probes for $€ 0.94$ and $€ 2.10$, respectively. Pradillon et al.'s (2007) technique does not require the purchase of a specialized cell sorter and can be carried out in the field; however, samples still need to be counted manually under a microscope. In contrast, as the sorting step of our method is automated, it is best suited for rapidly sorting large volumes of samples.

\section{CONCLUSIONS}

FISH-CS provides a rapid way to sort zooplankton samples. The method is robust for plankton autofluorescence, and careful probe design allows speciesspecific identification of target species. Coupled FISH has been used extensively for identifying and counting marine bacteria and phytoplankton, and this method can now be applied to zooplankton.

Acknowledgements. Taylor Hatchery, Coast Seafoods and Whiskey Creek Hatchery provided larvae samples for testing. Special thanks go to G. Hofmann for generous support in the laboratory. Tissue samples for the dot blots were provided by C. Pierre and P. Valentich-Scott; some of the plankton samples were provided by C. Pierre. R. Gray and K. Lewis at Caltech. W. Bae, N. Portier and J. Thompson at Union Biometrica assisted us in early work with cell sorting. A. Moehring and K. Muirhead provided advice and assistance at different stages of the project. Thoughtful comments from 4 reviewers greatly improved the manuscript. This is contribution 364 from PISCO, the Partnership for Interdisciplinary Studies of Coastal Oceans, funded primarily by the David and Lucile Packard Foundation and Gordon and Betty Moore Foundation. This work was funded by the California Coastal Commission and the University of California through a Coastal Environmental Quality Initiative fellowship and a Henry Luce Foundation 'Science to Solutions' grant to E.A.H., California Sea Grant Development Grant R/ENV-149PD, and support from the David and Lucile Packard Foundation, Gordon and Betty Moore Foundation and Andrew W. Mellon Foundation to S.D.G. 


\section{LITERATURE CITED}

Beaugrand G (2005) Monitoring pelagic ecosystems using plankton indicators. ICES J Mar Sci 62:333-338

Beaugrand G, Luczak C, Edwards M (2009) Rapid biogeographical plankton shifts in the North Atlantic Ocean. Glob Change Biol 15:1790-1803

Becker BJ, Levin LA, Fodrie FJ, McMillan PA (2007) Complex larval connectivity patterns among marine invertebrate populations. Proc Natl Acad Sci USA 104:3267-3272

Bilodeau AL, Lankford WS, Kim TJ, Felder DL, Neigel JE (1999) An ultrasensitive method for detection of single crab larvae (Sesarma reticulatum) by PCR amplification of a highly repetitive DNA sequence. Mol Ecol 8:683-684

Boidron-Metairon IF (1988) Morphological plasticity in laboratory-reared echinoplutei of Dendraster excentricus (Eschscholtz) and Lytechinus variegatus (Lamarck) in response to food conditions. J Exp Mar Biol Ecol 119:31-41

Collier JL (2000) Flow cytometry and the single cell in phycology. J Phycol 36:628-644

Comtet T, Jollivet D, Khripounoff A, Segonzac M, Dixon DR (2000) Molecular and morphological identification of settlement-stage vent mussel larvae, Bathymodiolus azoricus (Bivalvia: Mytilidae), preserved in situ at active vent fields on the Mid-Atlantic Ridge. Limnol Oceanogr 45: 1655-1661

Culverhouse PF, Williams R, Benfield M, Flood PR and others (2006) Automatic image analysis of plankton: future perspectives. Mar Ecol Prog Ser 312:297-309

Davis CS, Gallager SM, Berman MS, Haury LR, Strickler JR (1992) The Video Plankton Recorder (VPR): design and initial results. Ergeb Limnol 36:67-81

Davis CS, Gallager SM, Marra M, Stewart WK (1996) Rapid visualization of plankton abundance and taxonomic composition using the Video Plankton Recorder. Deep-Sea Res II 43:1947-1970

- Deagle BE, Bax N, Patil JG (2003) Development and evaluation of a PCR-based test for detection of Asterias (Echinodermata: Asteroidea) larvae in Australian plankton samples from ballast water. Mar Freshw Res 54:709-719

Garland ED, Zimmer CA (2002) Techniques for the identification of bivalve larvae. Mar Ecol Prog Ser 225:299-310

> Gasol JM, Del Giorgio PA (2000) Using flow cytometry for counting natural planktonic bacteria and understanding the structure of planktonic bacterial communities. Sci Mar 64:197-224

Gloor GB, Preston CR, Johnsonschlitz DM, Nassif NA and others (1993) Type I repressors of P element mobility. Genetics 135:81-95

Goffredi SK, Jones WJ, Scholin CA, Marin R, Vrijenhoek RC (2006) Molecular detection of marine invertebrate larvae. Mar Biotechnol 8:149-160

Groben R, Medlin L (2005) In situ hybridization of phytoplankton using fluorescently labeled rRNA probes. Methods Enzymol 395:299-310

Hare MP, Palumbi SR, Butman CA (2000) Single-step species identification of bivalve larvae using multiplex polymerase chain reaction. Mar Biol 137:953-961

Hebert PDN, Cywinska A, Ball SL, DeWaard JR (2003) Biological identifications through DNA barcodes. Proc R Soc Lond B Biol Sci 270:313-321

Inoue K, Waite JH, Matsuoka M, Odo S, Harayama S (1995)

Editorial responsibility: Steven Morgan,

Bodega Bay, California, USA
Interspecific variations in adhesive protein sequences of Mytilus edulis, M. galloprovincialis, and M. trossulus. Biol Bull 189:370-375

> Le Goff-Vitry MC, Chipman AD, Comtet T (2007a) In situ hybridization on whole larvae: a novel method for monitoring bivalve larvae. Mar Ecol Prog Ser 343:161-172

$>$ Le Goff-Vitry MC, Jacquelin S, Comtet T (2007b) Towards tracking marine larvae with in situ hybridization. J Mar Biol Assoc UK 87:1077-1080

Levin LA (1990) A review of methods for labeling and tracking marine invertebrate larvae. Ophelia 32:115-144

Lindley JA, Batten SD (2008) Distribution and seasonal cycles of decapod crustacean larvae in Continuous Plankton Records from the North Pacific Ocean. J Mar Biol Assoc UK 88:443-451

> Livi S, Cordisco C, Damiani C, Romanelli M, Crosetti D (2006) Identification of bivalve species at an early developmental stage through PCR-SSCP and sequence analysis of partial 18S rDNA. Mar Biol 149:1149-1161

Longhurst AR (1967) The pelagic phase of Pleuroncodes planipes Stimpson (Crustacea, Galatheidae) in the California Current. Calif Coop Ocean Fish Investig Rep 11:142-154

Longhurst AR (1998) Ecological geography of the sea. Academic Press, San Diego, CA

> Ludwig W, Strunk O, Westram R, Richter L and others (2004) ARB: a software environment for sequence data. Nucleic Acids Res 32:1363-1371

Miller PE, Scholin CA (1996) Identification of cultured Pseudo-nitzschia (Bacillariophyceae) using species-specific LSU rRNA-targeted fluorescent probes. J Phycol 32:646-655

- Miller PE, Scholin CA (2000) On detection of Pseudonitzschia (Bacillariophyceae) species using whole cell hybridization: sample fixation and stability. J Phycol 36: 238-250

> Morgan TS, Rogers AD (2001) Specificity and sensitivity of microsatellite markers for the identification of larvae. Mar Biol 139:967-973

Mountfort D, Rhodes L, Broom J, Gladstone M, Tyrrell J (2007) Fluorescent in situ hybridisation assay as a speciesspecific identifier of the northern Pacific seastar, Asterias amurensis. N Z J Mar Freshw Res 41:283-290

Pan M, McBeath AJA, Hay SJ, Pierce GJ, Cunningham CO (2008) Real-time PCR assay for detection and relative quantification of Liocarcinus depurator larvae from plankton samples. Mar Biol 153:859-870

Pernthaler J, Glöckner FO, Schönhuber W, Amann R (2001) Fluorescence in situ hybridization (FISH) with rRNAtargeted oligonucleotide probes. Methods Microbiol 30: $207-226$

Pradillon F, Schmidt A, Peplies J, Dubilier N (2007) Species identification of marine invertebrate early stages by whole-larvae in situ hybridisation of $18 \mathrm{~S}$ ribosomal RNA. Mar Ecol Prog Ser 333:103-116

Turbeville JM, Schulz JR, Raff RA (1994) Deuterostome phylogeny and the sister group of the chordates: evidence from molecules and morphology. Mol Biol Evol 11: 648-655

> Vadopalas B, Bouma JV, Jackels CR, Friedman CS (2006) Application of real-time PCR for simultaneous identification and quantification of larval abalone. J Exp Mar Biol Ecol 334:219-228

Submitted: November 26, 2009; Accepted: May 7, 2010

Proofs received from author(s): June 21, 2010 